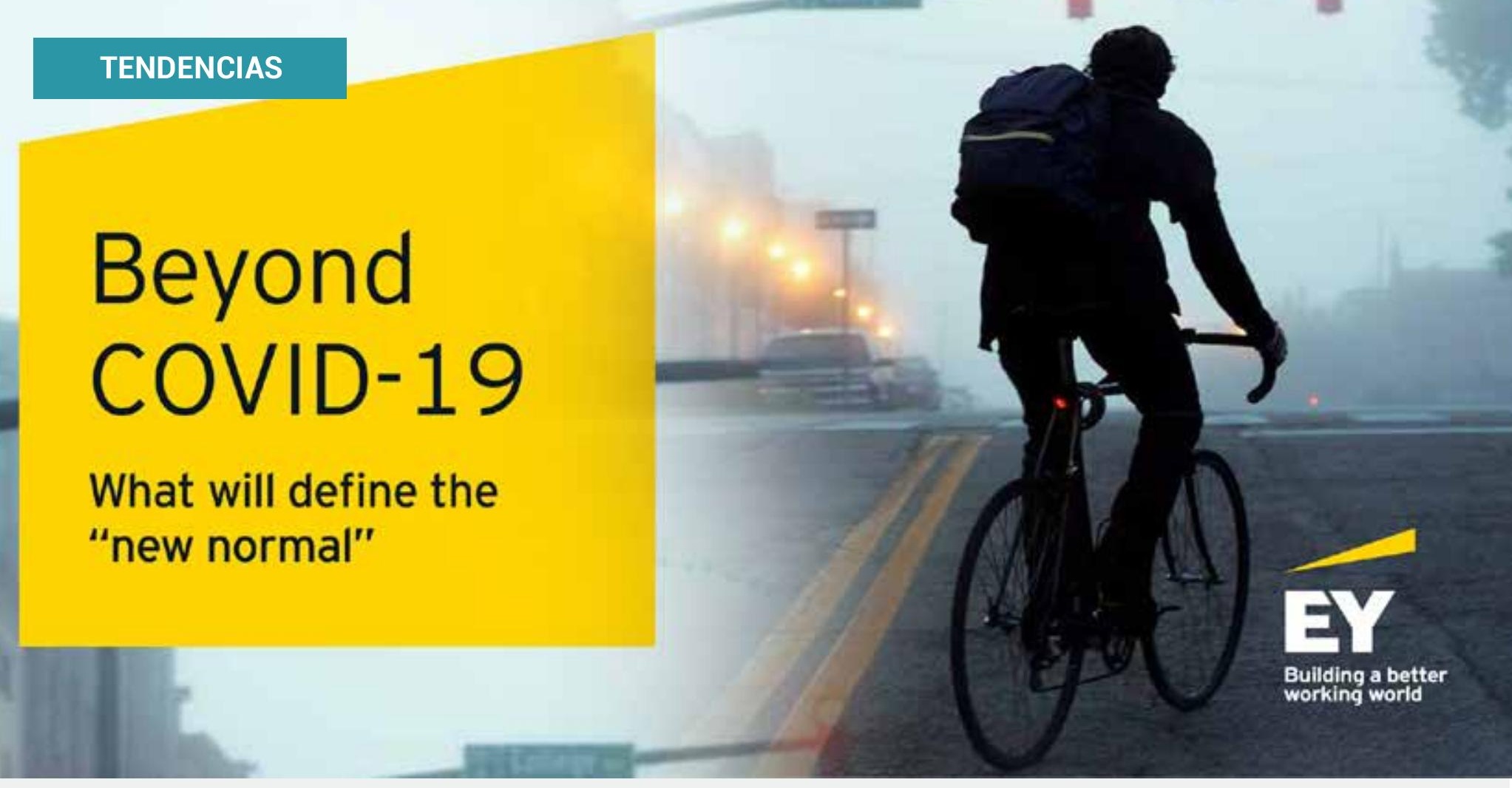

\title{
Background
}

The COVID-19 pandemic is a global crisis of historic proportions. What lasting impact will it have? With crises past, we've seen that even as things recover, each crisis leaves behind permanent structural changes. The Black Death of the 14th century rewrote the human genome in ways that are visible to this day. The 1918 Global Flu Pandemic helped topple empires. The Global Recession of 2007-09 precipitated changes - from workplace automation to travel policies - that remained in place even as the economy recovered.

What will be the "new normal" that emerges in the wake of the COVID-19 crisis? How should CEOs and boards plan and prepare for the post- COVID-19 world even as they respond to the immediate crisis ahead? In this document, EYQ, EY's think tank, has provided some insights into the new normal that lies beyond the COVID-19 pandemic, and what considerations business leaders should factor into planning for the new normal today. 
In an era of rapid disruption and business transformation, business leaders are simultaneously balancing short-term and long-term objectives. We look at this as operating across three horizons:

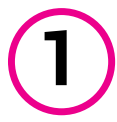

Solving the now: growing the existing business, maximizing profitability and shareholder value, and responding to immediate challenges

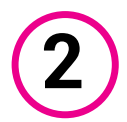

Exploring the next:
responding to
mediumterm
challenges and
opportunities,
largely from
disruptions in
your sector

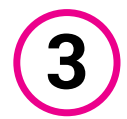

Imagining the beyond: responding to transformative, longterm challenges and opportunities from global, cross-sector megatrends

In the midst of a major crisis, the natural instinct is to double down on the now. When your enterprise's survival is at stake, responding to immediate threats takes on outsize importance. While that's understandable, it is also critical to keep one eye on the beyond, for the simple reason that large crises reshape the long-term competitive landscape. The world on the other side of the crisis may look very different, with different norms, rules, competitors and value propositions. Understanding the changes ahead can help you take steps now that are aligned with the world beyond the crisis.

To respond to the COVID-19 pandemic, companies should consider their strategy across the now, next and beyond:

1. Take steps now to stabilize your business, maintain continuity and manage the crisis.

This includes customer and brand protection, short-term finance management, supply chain management, workforce management and employee health, and legal and contract dispute resolution.

2. Focus on the next horizon, by building enterprise resilience to ensure you will be prepared across all functions if the crisis continues.

3. Ensure alignment with the beyond, by understanding the "new normal" that will emerge beyond the crisis and reframing your future to align with it.

The pandemic appears poised to unleash sweeping changes - reshaping the global economy, unleashing technological innovation, redefining society and companies' role in it, and altering consumers' needs and behaviors. Leaders should ensure they have dedicated teams responsible for tracking its long-term effects and thinking about the new normal. You may also want to look at other thought leadership from EY to help you with the challenges of the now and the next. 


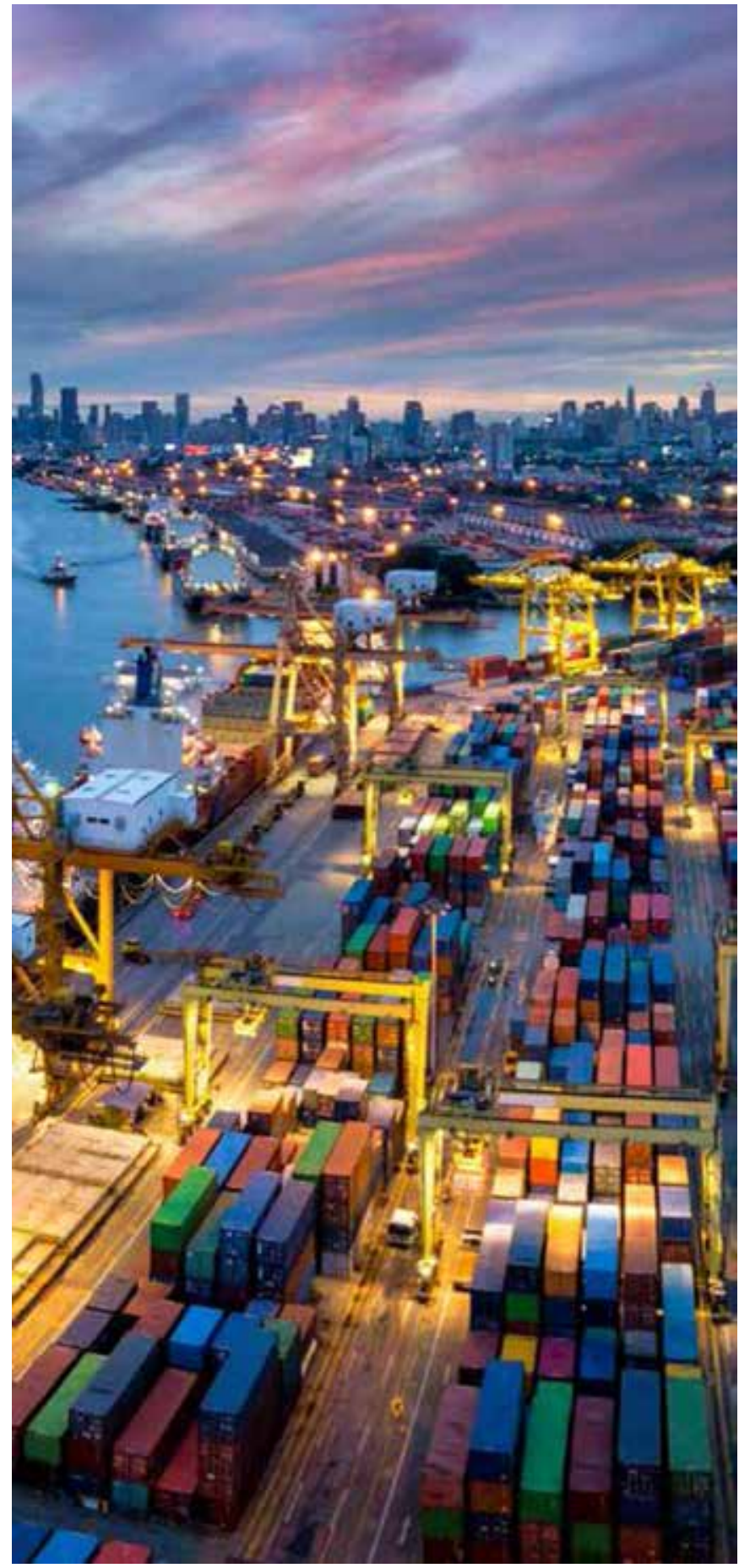

\section{Globalization and trade}

\section{Reorienting supply chains and manufacturing}

The COVID-19 pandemic is revealing how vulnerable global supply chains can be and will motivate companies to rethink their supply chain strategies. Specifically, a model in which businesses rely on a single supplier or a handful of suppliers concentrated in one country now appears particularly fragile.

In the medium-term, the pandemic will drive risk-mitigating procedures designed to track employee health, reduce humanto-human interactions, and upgrade ventilation and physical barriers. Companies could gain competitive advantage by adopting emerging automation technologies, such as robotics and artificial intelligence (Al) vision systems.

In the world beyond the crisis, the COVID-19 experience could accelerate the transition to approaches such as additive manufacturing (3D-printing) which has the potential to deliver significant advantages in speed, cost, precision and materials.

This, in turn, might enable new business models and reshape business models not just in manufacturing but also associated sectors such as logistics. It might also cause businesses to move from offshoring to near-shoring and even reshoring of production. This could boost the backlash against globalization that has been visible for the last few years.

In the medium-term, the pandemic will drive risk-mitigating procedures designed to track employee health, reduce human-to-human interactions, and upgrade ventilation and physical barriers. 


\section{Technology and innovation}

\section{Technology reshaping the working world}

COVID-19 will spur rapid technology adoption, potentially changing the working world. Fear of contagion is leading many to abandon cash in favor of digital payments. Social distancing is prompting organizations to embrace video conferencing, virtual classrooms and telemedicine at an unprecedented scale. As the crisis continues, it could accelerate development of next-gen remote working technologies, such as augmented and virtual reality. Since these technologies will generate efficiency gains, organizations may retain them beyond the crisis. This process will reshape entire industries and reframe the nature of work and learning. Companies may rethink their real estate strategy and footprint, new collaboration and teamwork models could emerge, and remote learning could redefine education.

Researchers are employing Al and synthetic biology in drug and vaccine R\&D. 3D printers are printing parts for ventilators, hands-free door openers and more.
Technologies that enable remote work and teaming also raise the risk of isolation and loneliness, which may negatively impact individual well-being and productivity. So, organizations will need to balance technology adoption with creative approaches to maintain a sense of community and meaning.

Technologies such as virtual and augmented reality could play a key role in achieving this balance.

\section{Emerging technologies fighting COVID-19}

New technologies and innovations often find their footing during times of crisis. The current crop of emerging technologies is no different; they are being put to the test in fighting COVID-19. The minimization of human-to-human interactions to prevent exposure to the virus is paving the way for automation. Robots are disinfecting rooms, communicating with the quarantined and delivering medications. Drones are patrolling public areas to conduct thermal imaging, spray disinfectant and ensure compliance with social distancing directives.

Surveillance technologies including facial recognition and mobile data are being deployed to track those infected and identify those that came into contact with them. Researchers are employing Al and synthetic biology in drug and vaccine R\&D. 3D printers are printing parts for ventilators, hands-free door openers and more. 


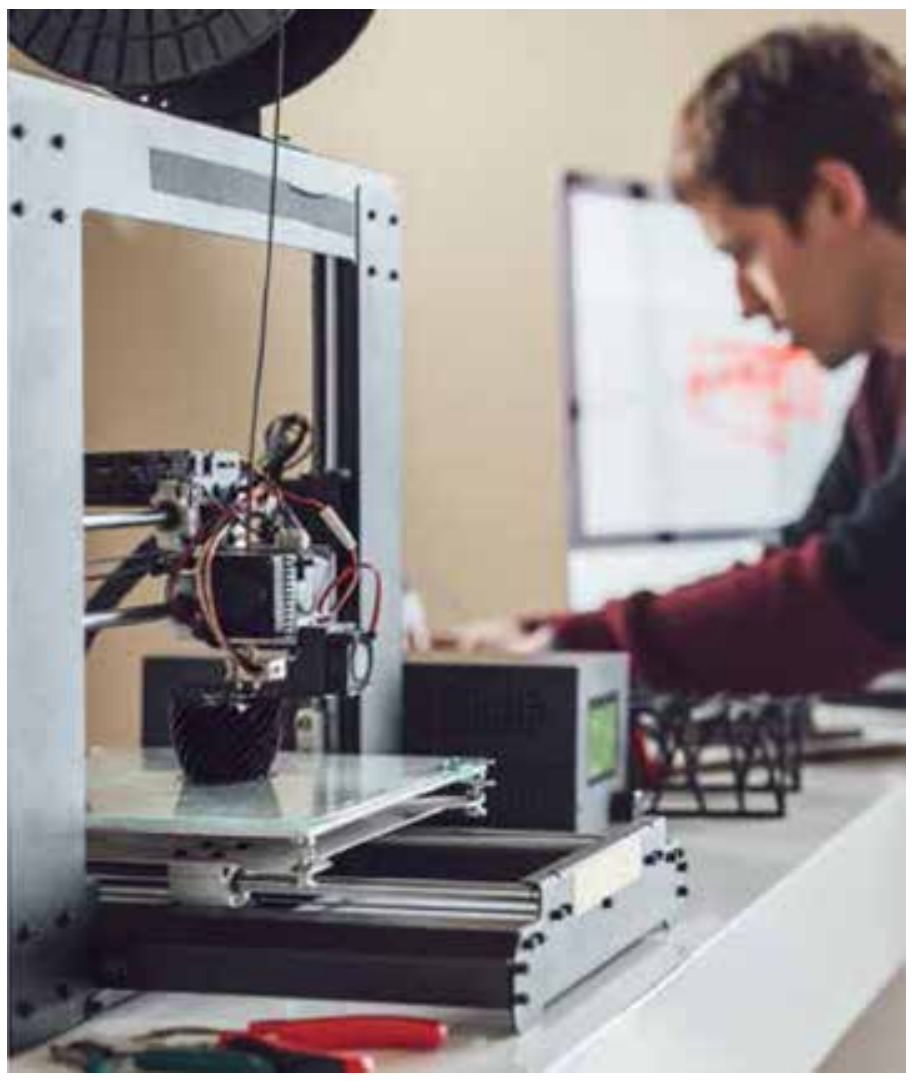

Some of these technologies have been under scrutiny due to ethical implications such as privacy, data rights and human autonomy. In the face of an existential crisis, consumers and regulators will likely place less emphasis on these privacy and ethical concerns. Beyond the crisis, it's possible that this permissive ethical mindset will become entrenched in the new normal. On the other hand, the ethical risks may gain visibility and urgency because these technologies are now widely deployed.

\section{Funded companies will be of higher quality and face less competition from venture-backed peers. Maintaining and building your ecosystem to tap into this innovation will be essential.}

\section{Innovating for the new normal}

Companies often react to economic dislocations by pursuing only the most immediate and largest revenue opportunities. While ensuring short-term viability comes first, short-changing innovation during this time could imperil long-term survival and value creation.

The last economic crisis, the Great Recession of 2007-09, saw transformational companies emerge in segments such as the sharing/gig economies and alternative currencies. This crisis will likely spur innovation that is every bit as transformative.

The discontinuities of crises like the COVID-19 pandemic create urgent new needs and new, large customer problems to solve - a huge innovation opportunity. As some big players retrench and focus on their most valuable customers, nimble innovators will find space to offer cheaper, "good enough" solutions that gain market traction. Look for disruption from below.

Downturns also create opportunities for entrepreneurs - and corporate intrapreneurs - to build great business ideas in capital efficient ways. Top talent becomes more accessible.

Support services become cheaper. A variety of assets, from real estate to equipment, becomes available for repurposing. If you don't build it, a disrupter will.

At the same time, venture capitalists will apply more stringent criteria to investing, focusing on the most compelling teams and funding fewer "me too" business plans. Funded companies will be of higher quality and face less competition from venture-backed peers. Maintaining and building your ecosystem to tap into this innovation will be essential.

Entrepreneurs are already beginning to innovate for the new normal. To participate and seize the upsides, large corporations must both address the short-term and innovate for long-term value. 


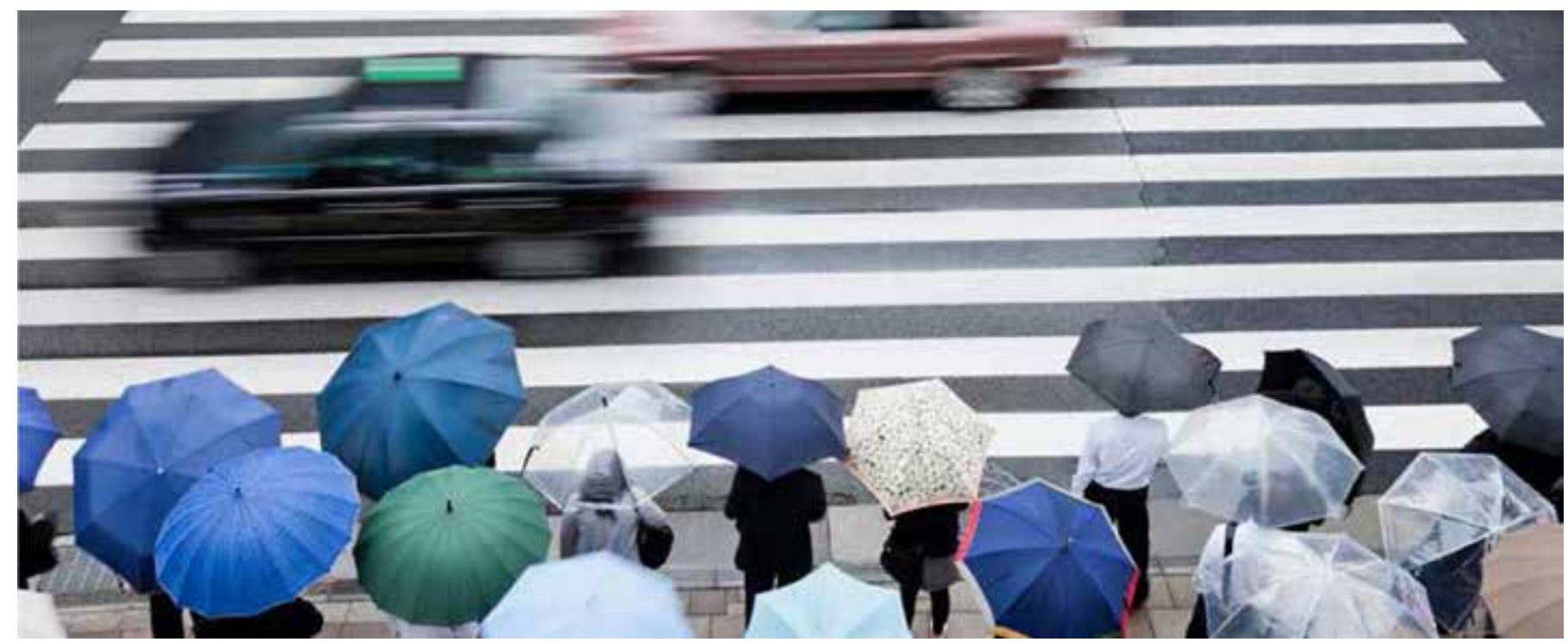

\section{Societal impacts}

\section{Strengthening safety nets}

The COVID-19 pandemic is highlighting the economic vulnerability of some segments of society - and demonstrating that the vulnerability of some increases the vulnerability of all.

In the US and most emerging markets, large segments of the population do not have access to health coverage which has raised questions about how such individuals would afford to get tested for the virus. Gig workers in the services sector are often in professions that place them at high risk of exposure to the virus, but also lack benefits such as paid sick leave.

This has raised concerns that workers would continue to come to work even if they were feeling unwell. In the megacities of the developing world, large populations of individuals live in cramped conditions with little access to good sanitation - calling into question the ability to effectively implement measures such as social distancing.

As the crisis has deepened and societies have moved from prevention to mitigation, more fault lines have become visible.

Social distancing mandates have led to large numbers of workers becoming unemployed practically overnight, straining safety net programs such as unemployment insurance. Once again, gig workers are particularly vulnerable, since they are not covered by such programs the way full-time employees are.
Policymakers from across the political spectrum are moving rapidly to enact measures to shore up safety nets. These changes could have staying power beyond the crisis.

Companies may find themselves operating in a world in which the safety net expectations of workers and societies have permanently shifted - along with their role in helping provide the safety net.

\section{Reexamining companies' role in society}

The COVID-19 pandemic will bring more attention to companies' societal roles and responsibilities. This issue has already been receiving considerable attention for some time now. Trust in businesses has declined in recent years even as consumers and investors call on companies to proactively address societal challenges, from income inequality to climate change.

The COVID-19 pandemic will increase scrutiny of this issue, in at least a couple of ways. First, companies across multiple sectors are playing an active role in addressing the challenges created by the crisis. Internet and wireless providers are delivering free wi-fi access to assist individuals working from home. News and media companies are taking down paywalls to expand access to life-saving information. Retailers are repurposing parking lots for drive-through testing clinics. Tech giants are donating millions of $\mathrm{N} 95$ masks to support frontline health care workers. Such visible moves could help burnish companies' reputations and restore dwindling trust. 
Second, business leaders should tread carefully with respect to bailouts, which policymakers will inevitably consider. This was a contentious issue in the Great Recession. While companies will start from a more sympathetic place this time as victims of a natural disaster, they will need to pay careful attention to the ways in which bailouts are handled in the political debate - and their own subsequent actions with respect to layoffs, executive bonuses and the like - which will shape public perception.

The increased cooperation between companies and governments could lead to a larger role for public-private partnerships in the new normal. The active part that companies are playing in addressing societal issues might also raise consumer expectations. Beyond the crisis, expect to be held to a higher standard about your societal responsibilities.

\section{Preparing for the post-pandemic generation}

For the generation coming up behind Gen $Z$, the postpandemic "new normal" will just be "normal." The impact of

this generational shift will likely be profound.

Generational cohorts are defined by societal changes during their formative years. Baby Boomers, for example, were born into rapid post-War economic growth and industrialization - imbuing them with tremendous confidence and optimism.

Gen Zers are the first digital natives and the first global cohort born into the climate emergency - making them more focused on climate issues than prior generations. Similarly, the children who never knew the world as it existed before the global pandemic will take for granted the transformations following in its wake - so the shifts described in this paper will apply to them in spades.

\footnotetext{
Companies may find themselves operating in a world in which the safety net expectations of workers and societies have permanently shifted - along with their role in helping provide the safety net.
}

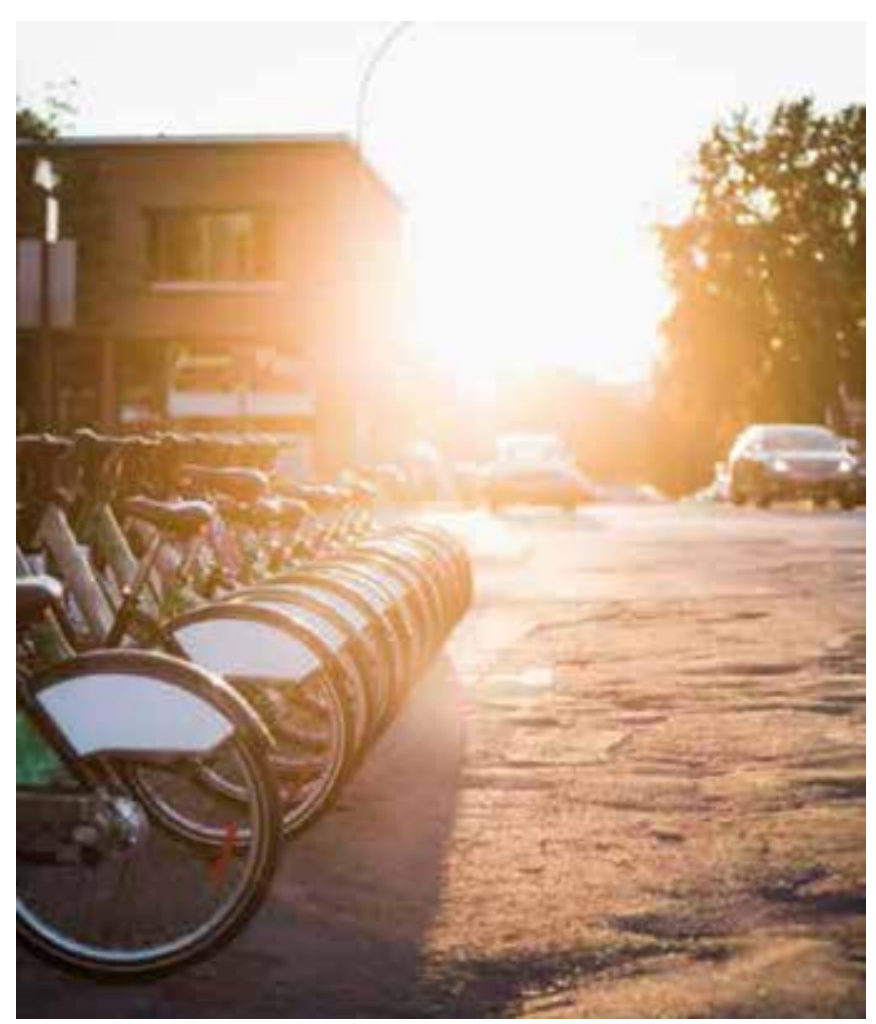

By 2030, there will be 2.7 billion people age 19 or younger. These individuals - at the cusp of college, entering the workforce, and with accelerating consumption power - will have little or no experience of a world before COVID-19.

Compared to their predecessors, this generation will likely bring very different assumptions and expectations related to society, technology and ethics, and the role of private companies in providing public goods.

Think of the business transformations - corporate purpose, sustainability, ways of working, use of digital, new businessmo dels - sparked by the emergence of Millennials and Gen Z. The next such transformation is on the horizon. The companies that make sense of the post-pandemic generation fastest will enjoy a competitive advantage in areas such as recruiting, productivity, innovation and customer. 


\section{Transforming consumer psychology}

It's inevitable for a lethal crisis to unleash psychological effects. Fear and uncertainty are already triggering irrationalacts, including herd behaviors such as stockpiling toilet paper. Consumers fear being unable to purchase necessities due to business interruptions and supply chain collapse.

Hoarding will likely dissipate with the easing of the crisis, but what lasting effects will the pandemic have on consumer psychology? Deep crises can leave lasting psychological scars, from the shell-shocked veterans of World War 1 to survivors of the Great Depression who were unable to trust banks for the rest of their lives. Will the profound isolation created by social distancing create a wave of consumers who prioritize in-person connection over social media? Will large numbers of casualties and a heightened awareness of mortality draw consumers to experiences rather than material possessions?

Will the pervasive sense of risk and uncertainty create a spike in demand for products and experiences that provide comfort? The COVID-19 pandemic will inevitably have lasting psychological impacts, and consumer psychology is no exception. Business leaders should track these changes and understand the needs of the new customer in the new normal. Behavioral economics could be invaluable here. Companies in many sectors have already been bringing behavioral expertise into boardrooms and executive offices; in the post-COVID-19 new normal, such capabilities should be even more valuable.

\section{Trust, polarization and information}

The Novel Coronavirus arrived when our social fabric is already badly frayed. Trust is low, and polarization is high while xenophobia is surging. We've seen a wide divergence in how individuals interpret news depending on their political leanings. Will the pandemic bring us closer together or drive us further apart?

Historically, pandemics have lowered social cohesion and spawned conflict. Riots broke out in Czarist Russia, Rio de Janeiro and the US-Mexican border after aggressive measuresere forced on populations as these governments battled the spread of cholera, smallpox, and typhoid respectively.

Governments enacting extreme measures to tackle COVID-19 may want to be mindful.
Behavioral economics could be invaluable here. Companies in many sectors have already been bringing behavioral expertise into boardrooms and executive offices; in the post-COVID-19 new normal, such capabilities should be even more valuable.

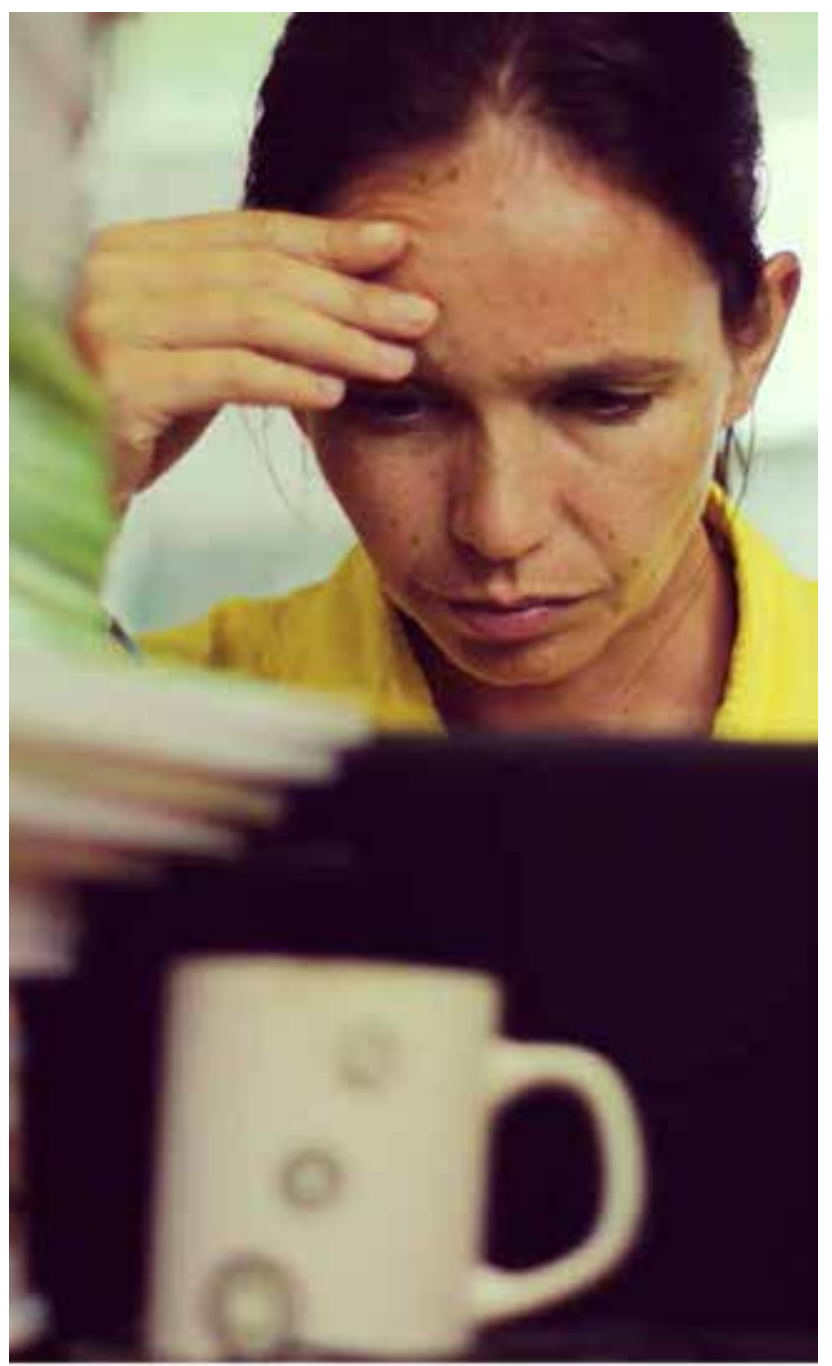




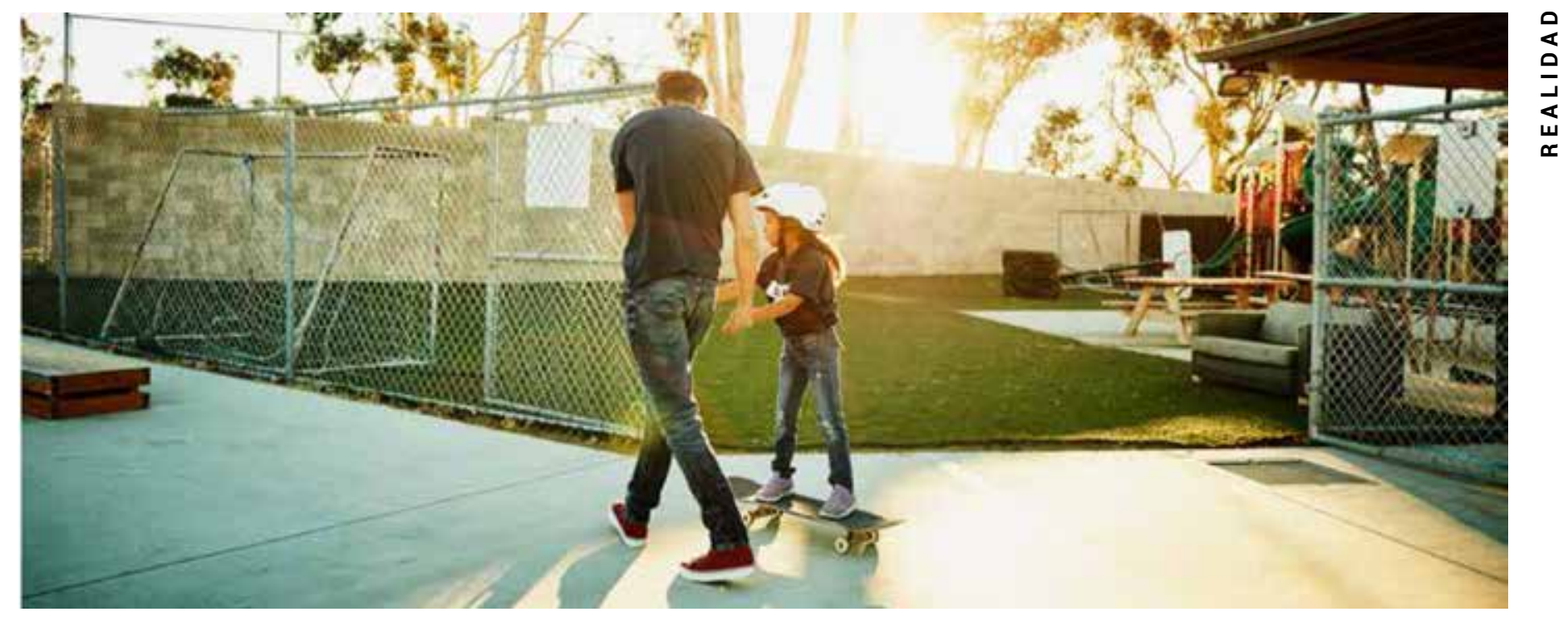

Framing a crisis as a collective challenge rather than blaming one group can make a huge difference. Jews were scapegoated and persecuted for the Black Death in Europe.

In early 20th century Norway, natural disasters (for which no humans could be blamed) prompted resilience, while the 1918 pandemic (blamed on infected people) led to a lasting breakdown in social cohesion. Business and government leaders should quell any attempts to blame a single ethnic group or nationality for COVID-19.

At a time when companies are being called on to assume a broader societal role, business leaders can lead by tackling misinformation, combating scapegoating and applying their capabilities to tackle the urgent challenges ahead.
How might the pandemic affect our highly polarized environment and the perception of social media? So far, social media has disseminated both valuable facts as well as misinformation. Platforms are taking serious and visible steps to combat COVID-19 misinformation - which could buy them some goodwill. Early on, there were sharp divisions between liberals and conservatives with respect to how seriously they took COVID-19 information. But as the crisis deepens, both sides are increasingly focusing on a common set of facts - at least in the scientific realm. Will the pandemic help restore a shared reality? After all, a virus cares not for race, religion, nationality, or political affiliation.

This pandemic is a crisis unlike any we have seen in our lifetimes. Like all crises, it will bring out the best and the worst in us as a species. Entities across the globe are cooperating with unprecedented openness in the search for a vaccine or cure. At a time when companies are being called on to assume a broader societal role, business leaders can lead by tackling misinformation, combating scapegoating and applying their capabilities to tackle the urgent challenges ahead. At the same time, they should keep an eye on the many changes underway in the global economy, technology adoption, societal norms and consumer behavior - which will together shape the new normal that lies beyond the crisis. 


\title{
EY | Assurance | Tax | Transactions | Advisory
}

\begin{abstract}
About EY
EY is a global leader in assurance, tax, transaction and advisory services. The insights and quality services we deliver help build trust and confidence in the capital markets and in economies the world over. We develop outstanding leaders who team to deliver on our promises to all of our stakeholders. In so doing, we play a critical role in building a better working world for our people, for our clients and for our communities.

EY refers to the global organization, and may refer to one or more, of the member firms of Ernst \& Young Global Limited, each of which is a separate legal entity. Ernst \& Young Global Limited, a UK company limited by guarantee, does not provide services to clients. Information about how EY collects and uses personal data and a description of the rights individuals have under data protection legislation are available via ey.com/privacy. For more information about our organization, please visit ey.com.
\end{abstract}

\section{About EYQ}

EYQ, EY's global think tank, generates new insights by bringing together business, the public sector and academia to challenge entrenched thinking, shift perceptions and help catalyze change. We want to sense new trends early, and understand and communicate their implications quickly and powerfully. By seeking the answer to "What's after what's next?", we help leaders anticipate the forces shaping our future empowering them to seize the upside of disruption and build a better working world.

\section{(C) 2020 EYGM Limited.}

All Rights Reserved.

EYG no. 001497-20Gbl

BMC Agency

GA 1015189

ED None

In line with EY's commitment to minimize its impact on the environment, this document has been printed on paper with a high recycled content.

This material has been prepared for general informational purposes only and is not intended to be relied upon as accounting, tax or other professional advice. Please refer to your advisors for specific advice.

\section{ey.com}

